\title{
Changes in Expression of Vascular Endothelial Growth Factor and Its Receptors in Neonatal Hypoxia-Induced Pulmonary Hypertension
}

\author{
SOPHIE NADEAU, JOHANNE BARIBEAU, ANNIE JANVIER, AND THÉRÈSE PERREAULT \\ Division of Newborn Medicine, Department of Pediatrics, Montreal Children's Hospital, McGill \\ University, Montreal, Quebec, Canada H3H 1P3
}

\begin{tabular}{|c|c|}
\hline \multicolumn{2}{|c|}{ ABSTRACT } \\
\hline $\begin{array}{l}\text { Vascular endothelial growth factor (VEGF) is a potent mito- } \\
\text { gen with angiogenic and vasoactive properties. VEGF can bind } \\
\text { to two types of receptors. VEGF receptor } 2 \text { (VEGFR2) is mainly } \\
\text { responsible for the dilator response to VEGF through nitric oxide } \\
\text { (NO) release, whereas VEGFR1 may sequestrate the ligand. We } \\
\text { hypothesized that in neonatal hypoxia-induced pulmonary hyper- } \\
\text { tension, VEGF vasodilation is reduced. The dilator response to } \\
\text { VEGF was assessed in isolated perfused lung of 1-d-old piglets } \\
\text { that were exposed to either normoxia or hypoxia (fraction of } \\
\text { inspired oxygen } 0.10 \text { ) for } 14 \text { d. The plasma and pulmonary artery } \\
\text { concentration of VEGF was measured by quantitative sandwich } \\
\text { enzyme immunoassay in piglets that were exposed to either } \\
\text { normoxia or hypoxia for } 1,3 \text {, } 7 \text {, or } 14 \text { d. The expression of } \\
\text { VEGFR1, VEGFR } 2 \text {, and endothelial NO synthase in pulmonary } \\
\text { artery was measured in the same study groups using Western blot } \\
\text { analysis. VEGF (10 } 12-10^{-9} \text { M) induces a dose-dependent re- } \\
\text { laxation in } 14-\mathrm{d} \text { normoxic piglets, whereas vasodilation is abol- } \\
\text { ished after } 14 \mathrm{~d} \text { of hypoxia. VEGF tissue concentration is } \\
\text { increased by hypoxia. VEGFR1 expression is dramatically in- } \\
\text { creased after } 1,3 \text {, and } 7 \text { d of hypoxia compared with normoxia } \\
\text { and returns to normal afterward. VEGFR } 2 \text { expression is reduced } \\
\text { by hypoxia at } 14 \text { d. However, endothelial NO synthase expres- }\end{array}$ & $\begin{array}{l}\text { sion is not affected by hypoxia compared with normoxia. In } \\
\text { neonatal hypoxia-induced pulmonary hypertension, VEGF is } \\
\text { increased, whereas vasodilation to VEGF is abolished. This } \\
\text { reduced vasodilation may be due to decreased VEGFR2 expres- } \\
\text { sion. We speculate that sequestration by VEGFR1 may also } \\
\text { limit, to some extent, the vascular protecting effect of VEGF, } \\
\text { thus contributing to the pathophysiologic changes seen in neo- } \\
\text { natal hypoxia-induced pulmonary hypertension. (Pediatr Res 58: } \\
\text { 199-205, 2005) } \\
\text { eNOS, endothelial nitric oxide synthase } \\
\text { FIO } \text {, fraction of inspired oxygen } \\
\text { iNOS, inducible nitric oxide synthase } \\
\text { LV+S, left ventricle plus septum } \\
\text { NO, nitric oxide } \\
\text { PECAM, platelet endothelial cell adhesion molecule } \\
\text { PPHN, persistent pulmonary hypertension of the newborn } \\
\text { RV, right ventricle } \\
\text { VEGF, vascular endothelial growth factor } \\
\text { VEGFR, vascular endothelial growth factor receptor }\end{array}$ \\
\hline
\end{tabular}

Vascular endothelial growth factor (VEGF) is a potent endothelial mitogen with angiogenic, vascular permeability, and vasoactive properties (1-3). VEGF exists as at least five isoforms (121-, 145-, 165-, 189-, and 206-amino acid isoforms) generated by alternate splicing of a single gene (1-3). $\mathrm{VEGF}_{165}$, a $46-\mathrm{kD}$ protein, is the most potent of the isoforms and is abundantly expressed in the lung vascular smooth muscle cells, macrophages, and epithelial cells (4). It is critical to early vascular development because gene ablation of a single

Received July 28, 2004; accepted November 30, 2004.

Correspondence: Thérèse Perreault, M.D., Montreal Children's Hospital, Newborn Medicine, 2300 Tupper Street, Montreal, Quebec, Canada, H3H 1P3; e-mail: therese.perreault@muhc.mcgill.ca.

This work was supported by the Canadian Institutes of Health Research (53137).

DOI: 10.1203/01.PDR.0000169969.18669.D2 allele of VEGF in the mouse prevents normal vascular development and causes early embryonic lethality $(5,6)$.

In the vascular system, two types of receptors are encountered: VEGF receptor 1 (VEGFR1; also called Flt-1) and VEGFR2 (also called Flk-1/KDR) both are tyrosine kinase receptors located on endothelial cells. VEGFR2 is initially synthesized as a $150-\mathrm{kD}$ protein, rapidly glycosylated to a 200-kD intermediate form, and then further glycosylated, at a slower rate, to a $230-\mathrm{kD}$ mature form expressed at cell surface (7). The overall processing steps are essentially the same for VEGFR1. Both receptors bind VEGF with high affinity, but VEGFR1 has the highest affinity for $\mathrm{VEGF}_{165}$, with a dissociation constant of $\sim 10-20 \mathrm{pM}$. VEGFR2 has a lower affinity with a dissociation constant of $\sim 75-125 \mathrm{pM}(2,8)$ and is responsible for the dilator response to VEGF (9). In fact, at 
least part of the dilator response to VEGF has been ascribed to induction of nitric oxide (NO) release (10). Of interest, a soluble form of VEGFR1 also exists; it is secreted by endothelial cells and was shown to inhibit VEGF activity in vitro by sequestering the ligand (1,11-13).

At birth, with the initiation of ventilation, pulmonary vascular resistance decreases markedly (14). Persistent pulmonary hypertension of the newborn (PPHN) is a clinical syndrome characterized by abnormal pulmonary vascular tone, reactivity, and structure, leading to persistent elevation of pulmonary vascular resistance and severe hypoxemia at birth $(15,16)$. In human newborns with PPHN, circulating levels of VEGF are reduced (17). In adult models of hypoxia-induced pulmonary hypertension using rats, it was shown that lung VEGF overexpression protects against pulmonary hypertension (9), whereas treatment with a VEGFR2 inhibitor (SU-5416) causes pulmonary hypertension and vascular remodeling (19). Recently, controversy has been raised by two studies done in fetal lambs using a model of increased pulmonary blood flow to induce pulmonary hypertension. In the whole lung, one study reported that VEGF expression is down-regulated (20), whereas the other noted that VEGF, VEGFR1, and VEGFR2 expression is up-regulated (21). Although, the exact role of VEGF and its receptors in the development of neonatal pulmonary hypertension remains obscured, Le Cras et al. (22) showed that inhibition of VEGF function by SU-5416 early in life causes pulmonary hypertension.

Knowing that maintenance of fetal levels of hypoxia postnatally results in intense vasoconstriction and vascular remodeling, preventing the decrease in vascular resistance that normally occurs at birth, we wanted to determine the contribution of the VEGF system in the development of neonatal hypoxiainduced pulmonary hypertension. We hypothesized that in the newborn undergoing hypoxic exposure, the vasoprotective effect of VEGF is blunted. Using the neonatal piglet model of hypoxia-induced pulmonary hypertension, we determined the effect of hypoxia on the ontogeny of pulmonary vascular expression/concentration of VEGF and its receptors, VEGFR1 and VEGFR2, and assessed the effect of hypoxia on the dilator response to VEGF. Furthermore, we assessed the expression of endothelial NO synthase (eNOS) and inducible NO synthase (iNOS) to determine whether we could establish a temporal link with the VEGF system. We report that pulmonary vascular levels of VEGF are increased by exposure to hypoxia, and these changes coincide with a decrease in VEGF-induced vasodilation. Furthermore, VEGFR1 and VEGFR2 expressions are transiently altered by hypoxia, possibly affecting the efficacy of VEGF.

\section{METHODS}

Animals. Experiments were performed with 1-d-old piglets with the approval of the Animal Care Committee of McGill University. As previously described (23-26), piglets were maintained in fraction of inspired oxygen $\left(\mathrm{FiO}_{2}\right) 0.10 \pm 0.005$ (hypoxia) or room air (control) for a period of $1,3,7$, or $14 \mathrm{~d}$ in a 440-L Plexiglas chamber. Hypoxia was achieved by a continuous mixture of separate sources of air and nitrogen (Floxal; VitalAire, Montreal, $\mathrm{PQ}$, Canada). $\mathrm{FIO}_{2}$ and fraction of inspired $\mathrm{CO}_{2}$ were measured at least three times per day with an electrochemical cell $\mathrm{O}_{2}$ analyzer (model S3-A/1; Ametek, Pittsburgh, PA) and sensor (model N-22M; Ametek) and an infrared
$\mathrm{CO}_{2}$ analyzer (model CD-3A; Ametek) and sensor (model P-61B; Ametek). $\mathrm{FIO}_{2}$ was also monitored continuously with an Oxychek oximeter (Critikon, Tampa, FL). Fraction of inspired $\mathrm{CO}_{2}$ was kept at $<0.005$ via adjustment of total gas flow. Piglets were maintained in a thermoneutral environment, and ambient temperature was adjusted $\left(26-36^{\circ} \mathrm{C}\right)$ according to age using a heater (model PCW-4; Noma, Scarborough, ON, Canada) with a temperature controller (model 689-0000; Barmant, Barrington, IL). Humidity level was maintained at $<70 \%$ using a condensing coil as a dehumidifier. A 12-h/12-h light/dark cycle was established, and animals were fed ad libitum with balanced artificial milk (Wet Nurser; Jefo Import Export, St-Hyacinthe, PQ, Canada). Daily care of the animals was done without interruption of hypoxia. Control piglets were raised under identical conditions, except that $\mathrm{FIO}_{2}$ was kept at 0.21 . Some normoxic animals were raised on the farm, as preliminary experiments did not reveal differences in measurements. All piglets received an intramuscular injection of iron in the immediate postnatal period. Animals from eight study groups were used either for isolation of arteries for peptide expression/concentration studies or for lung perfusion, in addition to cardiac weight measurements: group 1, 1-d normoxia $(n=10)$; group 2, 1-d hypoxia $(n=12)$; group 3, 3-d normoxia $(n=10)$; group 4, 3-d hypoxia $(n=11)$; group 5, 7-d normoxia $(n=6)$; group 6, 7-d hypoxia $(n=5)$; group 7, 14-d normoxia $(n=9)$; and group 8,14 -d hypoxia $(n=9)$. In animals that were not used for lung perfusion, the heart was removed and dissected into right ventricle (RV) and left ventricle plus septum $(L V+S)$. The ratio of $R V$ to $\mathrm{LV}+\mathrm{S}$, as an index of right ventricular hypertrophy, then was calculated. In 3and 14-d-old animals, blood was also withdrawn from the left ventricle to measure circulating VEGF.

Drugs. The Krebs solution used for the isolated lung experiments had the following composition (in mM): $119 \mathrm{NaCl}, 4.0 \mathrm{KCl}, 1.2 \mathrm{MgSO}_{4}, 1.2 \mathrm{KH}_{2} \mathrm{PO}_{4}$, $2.5 \mathrm{CaCl}_{2}, 5.5$ dextrose, and $25 \mathrm{NaHCO}_{3}$. The solution was supplemented with $50 \mathrm{~g} / \mathrm{L}$ albumin (BSA; Sigma Chemical Co. Chemical, St. Louis, MO). VEGF was provided by Dina Washington (Genentech, San Francisco, CA). The stable endoperoxide analog 9,11-dideoxy- $9 \alpha, 11 \alpha$-methano-epoxy prostaglandin $\mathrm{F}_{2 \alpha}$ (U-46619; Biomol Research Laboratories, Plymouth Meeting, PA), was used to raise the tone.

Tissue preparation. As described previously (23-25), lungs were excised and immersed in cold $\left(4^{\circ} \mathrm{C}\right)$ HEPES-buffered salt solution, which had the following composition (in mM): $20 \mathrm{HEPES}, 135 \mathrm{NaCl}, 2.68 \mathrm{KCl}, 1.8 \mathrm{CaCl}_{2}$, and $2.05 \mathrm{MgCl}_{2}$. After exposure of animals to normoxia or hypoxia for $1,3,7$, and $14 \mathrm{~d}$, pulmonary arteries were dissected from the hilum down to $100-\mu \mathrm{m}$ diameter. Arteries then were snap-frozen in liquid nitrogen and stored at $-80^{\circ} \mathrm{C}$ to be processed as whole-artery homogenate. A portion of the artery homogenate was used as is, and the other portion was used for subcellular fractioning. Thus, measurements on cellular fractions correspond to measurements that were obtained in homogenate as they originate from the same pool of vessels.

For each preparation, lungs from several animals $(n=1-4)$ were used. Tissues were ground and homogenized at $0-4^{\circ} \mathrm{C}$ in sample buffer that contained $50 \mathrm{mM}$ Tris-HCL, $250 \mathrm{mM}$ sucrose, $5 \mathrm{mM}$ EDTA, $10 \mathrm{mM}$ EGTA, 10 $\mathrm{mM}$ benzamidine, $50 \mu \mathrm{g} / \mathrm{mL}$ phenylmethylsulfonyl fluoride, $10 \mu \mathrm{g} / \mathrm{mL}$ leupeptin, and $5 \mathrm{mM}$ DTT, with a Polytron PT-3000 homogenizer (Brinkmann Instruments Canada, Rexdale, ON, Canada) at a speed of 13,500 rpm with six bursts of $20 \mathrm{~s}$ separated by 10 -s cooling intervals. The homogenate was centrifuged at $16,000 \times g$ for $30 \mathrm{~min}$ at $4^{\circ} \mathrm{C}$. The supernatant then was filtered through a $100-\mu \mathrm{m}$ mesh filter (Nytex, Zurich, Switzerland). This filtered fraction constituted the whole-artery homogenate.

For subcellular fractionation, the whole-artery homogenate was further centrifuged at $100,000 \times g$ for $1 \mathrm{~h}$ at $4^{\circ} \mathrm{C}$; the resulting supernatant constituted the cytosolic fraction, and the pellet represented the membrane fraction of cellular proteins. The microsomal pellet was resuspended in the sample buffer. Protein concentration was measured by the Bradford method. Preliminary experiments were conducted to determine whether specific proteins were better expressed in whole homogenate or in cytosolic or microsomal fraction. Therefore, protein contents of VEGFR2, eNOS, and iNOS were measured in whole-artery homogenate. VEGFR1 signal was markedly stronger in the cytosolic fraction compared with the whole homogenate. Therefore, VEGFR1 was measured in cytosolic and microsomal fractions. For comparison purposes, the endothelial cell marker platelet endothelial cell adhesion molecule (PECAM) and the smooth muscle cell marker $\alpha$-actin were assessed. PECAM was measured in the microsomal fraction, and $\alpha$-actin was measured in the whole-artery homogenate.

Western blot analysis. On each gel, one sample of each condition and duration of exposure was loaded. Equal amounts of samples $(15 \mu \mathrm{g}$ of protein) were resolved by the appropriate reduced SDS-PAGE and electrotransferred to polyvinylidene fluoride membranes. Prestained molecular weight protein markers were also loaded onto each gel. Posttransfer staining of the gel by Coomassie blue confirmed the efficacy of the transfer. Nonspecific binding sites of the membrane were blocked by 2-h incubation 
at room temperature with $5 \% \mathrm{wt} / \mathrm{vol}$ skim milk powder in PBS $(\mathrm{pH} 7.4)$ with $0.1 \%$ Tween 20 . Immunoblots were performed on the membranebound proteins at room temperature with incubation with rabbit polyclonal antibodies specific to VEGFR1 (1:500), VEGFR2 (1:200), eNOS (1:1000), iNOS (1:500), and PECAM (1:200; Santa Cruz Biotechnology, Santa Cruz, CA). A mouse MAb (1:25000, smooth muscle specific) was used to detect $\alpha$-actin (Calbiochem, San Diego, CA). Goat anti-rabbit and a goat antimouse antibody (BioRad, Hercules, CA) were used as second antibody (1:7500). Signal detection was done using enhanced chemiluminescence (ECL Plus; Amersham Life Sciences) on Hyperfilm ECL (Amersham Biosciences, Inc., Quebec, Canada). Their corresponding scans (HP ScanJet 5P, Mississauga, ON, Canada) were quantified with Fujifilm Science Lab 97 Image Gauge Version 3.0 software (Tokyo, Japan). The following size bands were obtained: 130, 200, and $230 \mathrm{kD}$ for VEGFR1; 150, 200, and $230 \mathrm{kD}$ for VEGFR2; $135 \mathrm{kD}$ for eNOS; $170 \mathrm{kD}$ for iNOS; $130 \mathrm{kD}$ for PECAM; and $43 \mathrm{kD}$ for $\alpha$-actin. Gels were also run in the presence of blocking peptides when available, i.e. VEGFR1, eNOS, and iNOS

Measurement of VEGF concentration in plasma and cytosol. After thoracotomy and before lung excision, blood was sampled from the left ventricle and placed in chilled tubes with EDTA. Blood was immediately centrifuged at $3000 \times \mathrm{g}$, at $4^{\circ} \mathrm{C}$ for $20 \mathrm{~min}$, and the plasma was stored at $-70^{\circ} \mathrm{C}$ until analyzed. Plasma VEGF concentration was measured by quantitative sandwich enzyme immunoassay technique, using QuantiGlo human VEGF immunoassay kits from R\&D Systems (Minneapolis, MN). For the measurement of VEGF in the cytosolic fraction of pulmonary arteries, the subcellular fraction was prepared as described above. Samples were analyzed in duplicate. Two antibodies, directed at different epitopes of the VEGF molecule, were used. An enhanced luminol/peroxide substrate solution was added, and the intensity of the light emitted was measured with a microplate luminometer (MicroLumat Plus LB96V; EG (Beid, Germany \& Berthold, Wildbad, Germany). The intra-assay coefficient of variation for the kit is $3-7 \%$. The sensitivity of the assay for VEGF is 0.78 $\mathrm{pg} / \mathrm{mL}$. The cross-reactivity with human $\mathrm{VEGF}_{165} / \mathrm{PlGF}$ heterodimer is $27 \%$.

Isolated perfused lung. Animals were anesthetized with sodium pentobarbital $\left(65 \mathrm{mg} / \mathrm{kg}\right.$, i.p.), tracheostomized, and ventilated with $25 \% \mathrm{O}_{2} / 5 \% \mathrm{CO}_{2}$ in $\mathrm{N}_{2}$ with a tidal volume of $20 \mathrm{~mL} / \mathrm{kg}$. The isolated-perfused lung preparation was set up as previously described (23-26). Briefly, a cannula was placed in the pulmonary artery, and lungs were perfused with Krebs solution supplemented with $5 \%$ albumin at a constant flow of $30 \mathrm{~mL} \cdot \min ^{-1} \cdot \mathrm{kg}$ body weight $^{-1}$ using a peristaltic pump (Masterflex, model 7553-30; Cole-Palmer, Chicago, IL). Perfusate drained by gravity through a cannula placed in the left ventricle. Throughout the experiments, perfusion pressure, which reflects pulmonary artery inflow pressure, was monitored with a transducer (mode P2310; Gould Instruments, Cleveland, $\mathrm{OH}$ ) and a chart recorder (model 7E; Grass Instruments, Quincy, MA). Baseline perfusion pressure has been shown previously to be stable for $\geq 2.5 \mathrm{~h}$. Integrity of the preparation was assessed by the stability of the baseline perfusion pressure and/or by the presence of edema as revealed by macroscopic examination.

Lung preparations were allowed to stabilize for $30 \mathrm{~min}$ after being mounted and perfused inside the chamber. After the stabilization period, for achieving comparable baseline pressure among all groups, vascular tone was raised as needed by adding to the perfusate the endoperoxide analog U-46619. The target pressure was $\sim 12 \mathrm{~mm} \mathrm{Hg}$. In hypoxic preparations, U-46619 was almost never required as tone was already at target level. VEGF then was added to the perfusion bath and was recirculated continuously through the preparation. An interval of at least 20 min was allowed between each concentration of VEGF tested in a cumulative manner.

Data analysis. Data are presented as means \pm SD. Statistical analysis of $\mathrm{RV}$-to-LV $+\mathrm{S}$ ratio was performed using ANOVA, with $p<0.05$ being considered significant. In normoxia, for standardizing the results between the different blots, protein expression at different ages was normalized against protein expression measured at day 1. In hypoxia, protein expression for each duration of exposure was expressed as a ratio of hypoxia over normoxia. For accounting for underrepresentation of endothelial cell proteins in the context of increased smooth muscle cell mass as a result of remodeling in hypoxia, expression in hypoxia over normoxia of VEGFR1, VEGFR2, eNOS, and iNOS was normalized against expression in hypoxia over normoxia of PECAM Ratios were calculated for each pool of arteries. Expressions of VEGFR1, VEGFR2, eNOS, iNOS, PECAM, and $\alpha$-actin as well as VEGF concentration were analyzed using two-tailed or one-tailed $t$ test as appropriate, with $p<$ 0.05 being considered significant.

The dilator response to VEGF was evaluated by measuring the lowest perfusion pressure reached for each concentration tested. The significance of the effect of VEGF on perfusion pressure at different concentrations was assessed statistically using ANOVA for repeated measures, with $p<0.05$ being considered significant.

\section{RESULTS}

Physiologic measurements. As expected, the $\mathrm{RV} / \mathrm{LV}+\mathrm{S}$ weight ratio decreased from day 3 to day 14 in normoxic piglets $(p<0.0001)$, whereas the ratio increased in hypoxic animals ( $p<0.0001$; Fig. 1). In fact, the $\mathrm{RV} / \mathrm{LV}+\mathrm{S}$ ratio was significantly increased after $3(p<0.005), 7(p<0.0001)$, and $14 \mathrm{~d}(p<0.0001)$ of exposure to hypoxia compared with normoxia.

VEGF concentration. Circulating VEGF was not affected by age or by exposure to hypoxia (Table 1). The cytosolic concentration of VEGF was not affected by age but was augmented by hypoxic exposure (Table 1).

Endothelial cell and smooth muscle cell markers. To assess whether our findings in hypoxic vessels were simply the result of changes in the proportion of endothelial cells versus smooth muscle cells induced by hypoxia, we evaluated the expression of the endothelial cell marker PECAM and the smooth muscle cell marker $\alpha$-actin. PECAM expression was measured in the microsomal fraction, whereas $\alpha$-actin expression was measured in the homogenate of piglet pulmonary arteries. PECAM and $\alpha$-actin expression remained stable during the first 2 wk of life (Figs. 2 and 3). In hypoxia, PECAM expression was decreased as exposure was prolonged, reaching significance at $3(p<0.05), 7$ ( $p<0.05)$, and $14 \mathrm{~d}(p<0.0005$; Fig. 3). Further supporting that hypoxia affects specifically certain proteins is that the expression of $\alpha$-actin was not affected by hypoxia (Fig. 3).

VEGFR1 expression. Three bands were identified at $\sim 130$, 200 , and $230 \mathrm{kD}$. The signal was remarkably stronger in cytosolic than in microsomal fraction. In fact, VEGFR1 expression in the microsomes was only $5 \%$ of the one measured in the cytosol, and for this reason, results of the microsomal fraction are not shown. In normoxia, the expression of the 230and $200-\mathrm{kD}$ bands increased with age (Fig. 4). However, the expression of the $130-\mathrm{kD}$ band was decreased. In hypoxia, the normalized expression against PECAM of all bands was dramatically increased after most durations of exposure to hypoxia (Fig. 4).

VEGFR2 expression. The expression of VEGFR2 was measured in piglet pulmonary artery homogenates. Three bands

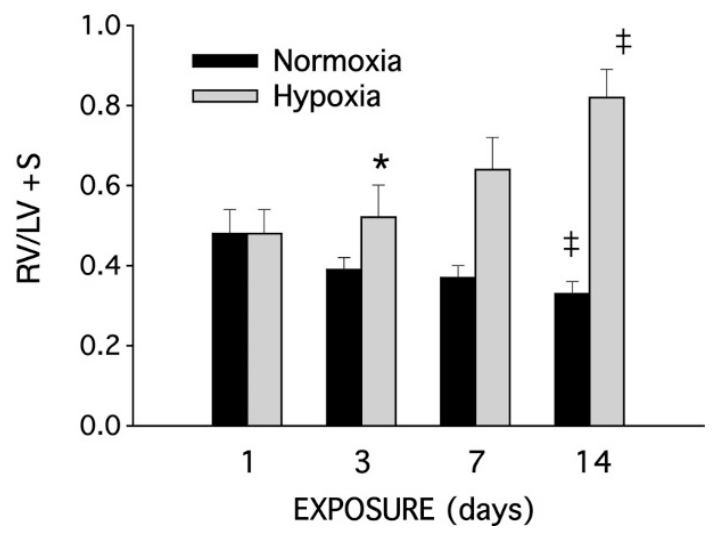

Figure 1. Comparisons of $\mathrm{RV} / \mathrm{LV}+\mathrm{S}$ in normoxic $(n=25)$ and hypoxic piglets $(n=32)$. Values are means $\pm \mathrm{SD} ;{ }^{*} p<0.005$ vs normoxic group of corresponding age; $\uparrow p<0.0001 v s$ normoxic group of corresponding age; $\ddagger p$ $<0.0001$ vs 3-d group of corresponding condition. 
Table 1. Concentrations of VEGF

\begin{tabular}{|c|c|c|c|c|c|}
\hline & & \multicolumn{4}{|c|}{ Age (days) } \\
\hline & & 1 & 3 & 7 & 14 \\
\hline \multirow[t]{2}{*}{ Plasma (pg/ml) } & Normoxia & & $46 \pm 19$ & & $37 \pm 16$ \\
\hline & Hypoxia & & $37 \pm 13$ & & $41 \pm 19$ \\
\hline \multirow[t]{2}{*}{ Cytosol (pg/mg prot) } & Normoxia & $18.2 \pm 2.8$ & $10.7 \pm 4.0$ & $8.1 \pm 4.8$ & $10.7 \pm 3.4$ \\
\hline & Hypoxia & $45.7 \pm 13.7[4] \dagger$ & $73.2 \pm 54.3[4]$ & $76.6 \pm 53.5[4]^{*}$ & $42.7 \pm 22.2[4]^{*}$ \\
\hline
\end{tabular}

Values are expressed as mean \pm SD; Nos. in parentheses denote the number of animals. Nos. in brackets denote the number of tissue preparations.

* Significantly different from normoxia of same duration of exposure, $p<0.05$.

$\dagger$ Significantly different from normoxia of same duration of exposure, $p<0.01$.
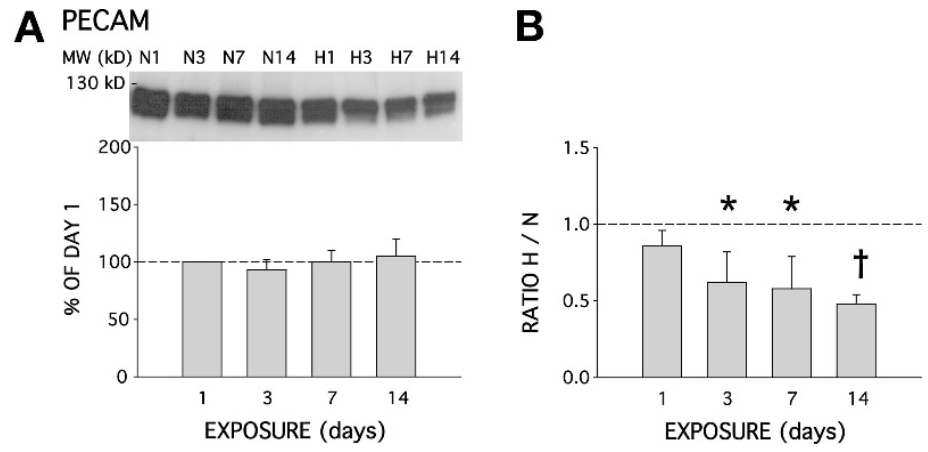

Figure 2. PECAM expression in pulmonary artery homogenate of piglets that were exposed to normoxia or hypoxia for $1,3,7$, or $14 \mathrm{~d}$. Values are means \pm $\mathrm{SD} ; n=4$. (A) Percentage of day 1 for different ages in normoxia. No difference was observed across ages. (B) Ratio of hypoxia $(\mathrm{H})$ over normoxia $(\mathrm{N})$ for each duration of exposure. A value less than one represents a decrease in hypoxia in comparison with normoxia. *Expression significantly reduced in hypoxia $(p<0.05)$; †expression significantly reduced in hypoxia $(p<$ 0.0005).
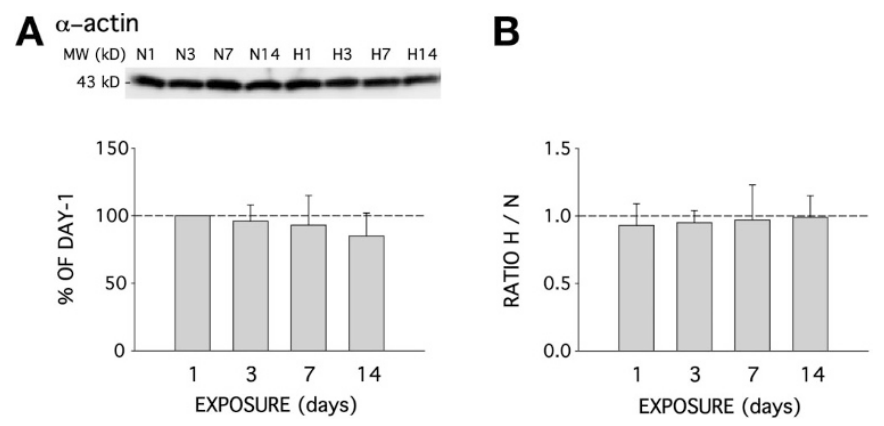

Figure 3. $\alpha$-Actin expression in pulmonary artery homogenate of piglets that were exposed to normoxia or hypoxia for $1,3,7$, or $14 \mathrm{~d}$. Values are means \pm SD; $n=4$. (A) Percentage of day 1 for different ages in normoxia. No difference was observed across ages. $(B)$ Ratio of hypoxia $(\mathrm{H})$ over normoxia $(\mathrm{N})$ for each duration of exposure. A value less than one represents a decrease in hypoxia in comparison with normoxia. Expression was not affected by hypoxia.

were also identified at $\sim 150,200$, and $230 \mathrm{kD}$ (Fig. 5). In normoxia, the expression of these three bands was not developmentally changed. However, when animals were exposed to hypoxia, the normalized expression of the $230-\mathrm{kD}$ band against PECAM was dramatically reduced at $14 \mathrm{~d}(p<0.05)$. The normalized expression of the $200-\mathrm{kD}$ band was not affected by hypoxia, but the expression of the $150-\mathrm{kD}$ band was augmented at all ages $(p<0.05)$.

eNOS expression. The expression of eNOS was measured in piglet pulmonary artery homogenates. In normoxia, eNOS expression was slightly reduced in 3- and 7-d animals $(p<$

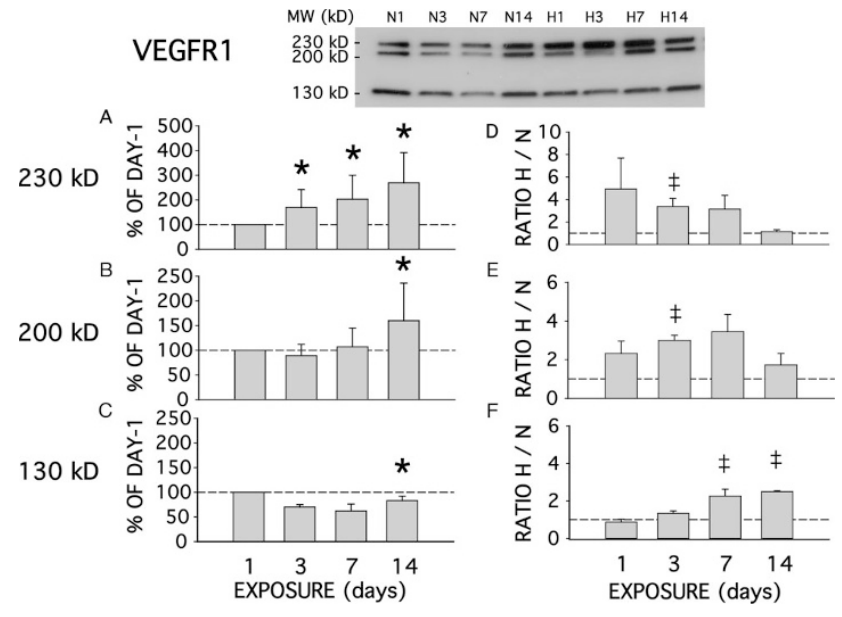

Figure 4. VEGFR1 expression in pulmonary artery cytosolic fraction of piglets that were exposed to normoxia or hypoxia for 1, 3, 7, and $14 \mathrm{~d}$. Three different bands were identified at 230, 200, and $130 \mathrm{kD}$; values are means \pm $\mathrm{SD} ; n=3$. $(A-C)$ Percentage of day 1 for different ages in normoxia. *Expression significantly altered compared with day $1(p<0.05)$; †expression significantly changed compared with day $1(p<0.005)$. $(D-F)$ Ratio of the expression of hypoxia $(\mathrm{H})$ over normoxia $(\mathrm{N})$ over the expression of hypoxia over normoxia of PECAM for each duration of exposure. A value less than one represents a decrease in hypoxia in comparison with normoxia. significantly increased in hypoxia $(p<0.005)$; §expression significantly different in hypoxia $(p<0.05)$.

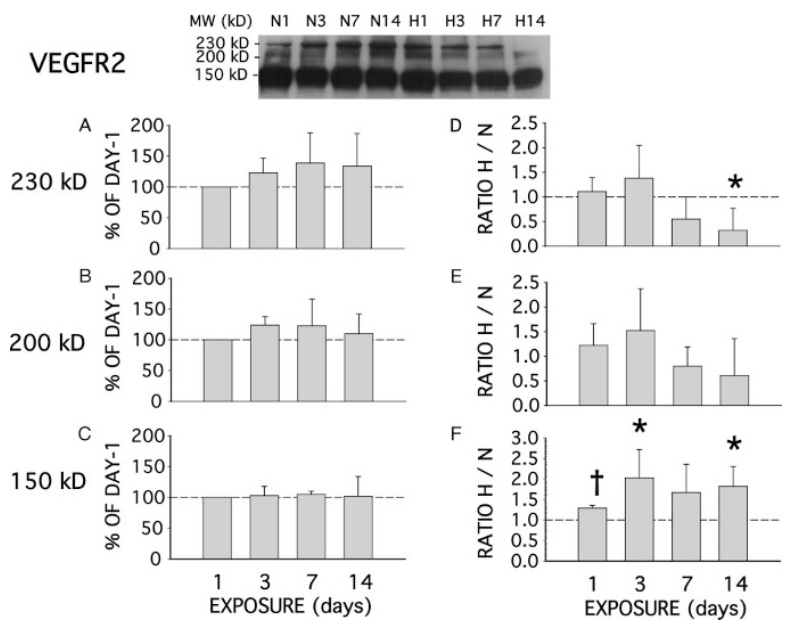

Figure 5. VEGFR2 expression in pulmonary artery homogenate of piglets that were exposed to normoxia or hypoxia for $1,3,7$, and $14 \mathrm{~d}$. Three different bands were identified at 230, 200, and $150 \mathrm{kD}$; values are means $\pm \mathrm{SD} ; n=$ 4. $(A-C)$ Percentage of day 1 for different ages in normoxia. $(D-F)$ Ratio of the expression of hypoxia $(\mathrm{H})$ over normoxia $(\mathrm{N})$ over the expression of hypoxia over normoxia of PECAM for each duration of exposure. A value less than one represents a decrease in hypoxia in comparison with normoxia. *Expression significantly altered in hypoxia $(p<0.05)$; †expression significantly increased in hypoxia $(p<0.005)$. 
A ${ }^{\text {eNOS }}$

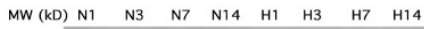
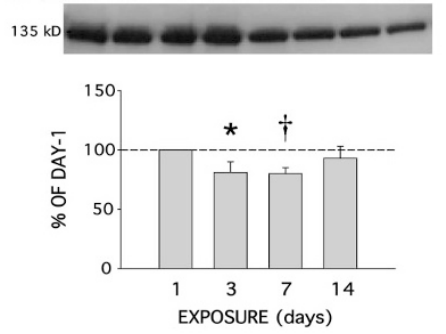

B

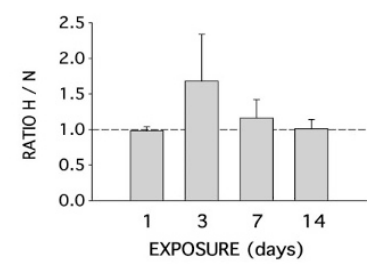

Figure 6. eNOS expression in pulmonary artery homogenate of piglets that were exposed to normoxia or hypoxia for $1,3,7$, or $14 \mathrm{~d}$. Values are means \pm $\mathrm{SD} ; n=4$. (A) Percentage of day 1 for different ages in normoxia. *Expression significantly reduced at day $3(p<0.05)$; †expression significantly decreased at day $7(p<0.005)$. (B) Ratio of the expression of hypoxia $(\mathrm{H})$ over normoxia $(\mathrm{N})$ over the expression of hypoxia over normoxia of PECAM for each duration of exposure. A value less than one represents a decrease in hypoxia in comparison with normoxia.

A ${ }^{\text {NOS }}$

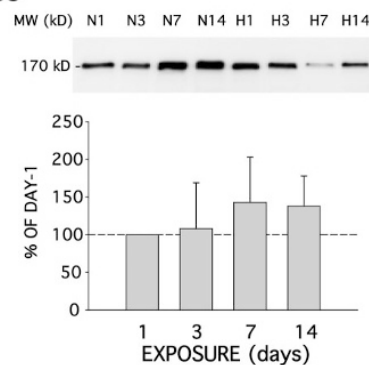

B

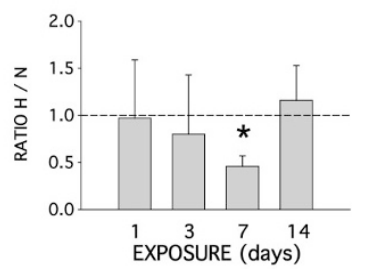

Figure 7. iNOS expression in pulmonary artery homogenate of piglets that were exposed to normoxia or hypoxia for $1,3,7$, or $14 \mathrm{~d}$. Values are means \pm $\mathrm{SD} ; n=4$. (A) Percentage of day 1 for different ages in normoxia. No difference was observed across ages. $(B)$ Ratio of the expression of hypoxia $(\mathrm{H})$ over normoxia $(\mathrm{N})$ over the expression of hypoxia over normoxia of PECAM for each duration of exposure. A value less than one represents a decrease in hypoxia in comparison with normoxia. *Expression significantly reduced in hypoxia $(p<0.05)$.

0.05 and $p<0.01$, respectively; Fig. 6). Hypoxic exposure did not affect the normalized eNOS expression.

iNOS expression. The expression of iNOS was measured in piglet pulmonary artery homogenates. In normoxia, iNOS expression was not developmentally affected (Fig. 5). However, hypoxic exposure diminished normalized iNOS expression at 7 d $(p<0.05$; Fig. 7$)$.

Pulmonary vascular response to VEGF. Baseline perfusion pressure was increased in animals that were raised in hypoxia compared with those in normoxia $(11.5 \pm 1.4$ versus $6.4 \pm 1.4$ $\mathrm{mm} \mathrm{Hg} ; p<0.05)$. VEGF $\left(10^{-11}-10^{-9} \mathrm{M}\right)$ caused a dosedependent relaxation in normoxic piglets (Fig. 8). The dilator response started after 1 to $2 \mathrm{~min}$ of infusion, peaked at $\sim 5 \mathrm{~min}$, and was partially or completely reversed at $20 \mathrm{~min}$. When animals were exposed to hypoxia for $14 \mathrm{~d}$, vasodilation to VEGF was completely abolished ( $p<0.05$; Fig. 8$)$.

\section{DISCUSSION}

This is the first report to suggest that in the neonatal piglet pulmonary vasculature, chronic hypoxia is associated with multiple disruptions in the integrity of the VEGF pathway.

Whereas the cytosolic concentration of VEGF is increased in hypoxic pulmonary arteries, there is a reduction in VEGFR2 expression in the whole vascular bed, an increase in VEGFR1 expression, and an abolishment of the vasodilator response to VEGF.

As we have shown previously (23-26), the exposure to chronic hypoxia soon after birth prevents the decrease in pulmonary vascular resistance and induces significant pulmonary hypertension. The presence of an increased ratio of RV/ $\mathrm{LV}+\mathrm{S}$ weight after only $3 \mathrm{~d}$ of hypoxic exposure further demonstrates that these changes occur rapidly.

In the present study, we have found that chronic hypoxia is associated with unchanged circulating levels of VEGF in the neonatal piglet, whereas in the pulmonary vasculature, VEGF concentration is increased. Unlike us, Lassus et al. (17) reported decreased circulating plasma levels of VEGF in human infants with PPHN. Others have reported, as in our cytosolic measurements, that VEGF is augmented. For example, MataGreenwood et al. (21) noted that whole-lung VEGF expression was increased in a fetal lamb model of pulmonary hypertension with increased pulmonary blood flow. In addition, lung VEGF expression was found to be increased in the adult rat with hypoxia-induced pulmonary hypertension $(27,28)$. Furthermore, VEGF was augmented in lungs of newborn infants with congenital diaphragmatic hernia and pulmonary hypertension (29). However, Grover et al. (20) recently described a marked reduction in whole-lung VEGF expression in a fetal lamb model of neonatal pulmonary hypertension with increased pulmonary blood flow. The conflicting results noted between this study and our experiment may represent a species-, a model-, a site-, or an antibody type-related difference.

We have shown that in normoxia, VEGFR1 expression increases with age. The reason for this increase in the postnatal period remains to be determined but may represent another way of regulating angiogenesis. Because of its higher binding affinity with VEGF, it has been suggested that VEGFR1 sequesters VEGF, thus preventing its binding to VEGFR2 $(2,8)$. VEGFR1 transcription can be stimulated directly in endothelial cells in response to hypoxia via HIF-1 $\alpha$ (1). In our model, VEGFR1 expression is rapidly induced by hypoxia, and this increase is real as it persisted after normalization against PECAM. Thus, the dilutional effect on endothelial cell proteins by the increase in smooth muscle cell proteins is accounted for by normalizing against PECAM. However, Mata-Greenwood et al. (21) reported a later rise in VEGFR1 in a different model of pulmonary hypertension. Whether this increased VEGFR1 expression is due to increased transcription or translation in our animal model remains to be determined. In our experiments, VEGFR1 expression was remarkably strong in cytosol and very weak in microsomes. However, the majority of VEGFR1 expression should lie within the membrane fraction (1). Contamination of the cytosolic fraction with microsomes could not explain our results, as the signal was weak in the microsomes. A soluble form of VEGFR1, lacking the seventh Ig-like domain, transmembrane sequence, and cytoplasmic domain, has been identified in human umbilical vein endothelial cells $(12,13)$. It is possible that the higher molecular band of VEGFR1 found in the cytosolic fraction corresponds in fact to 


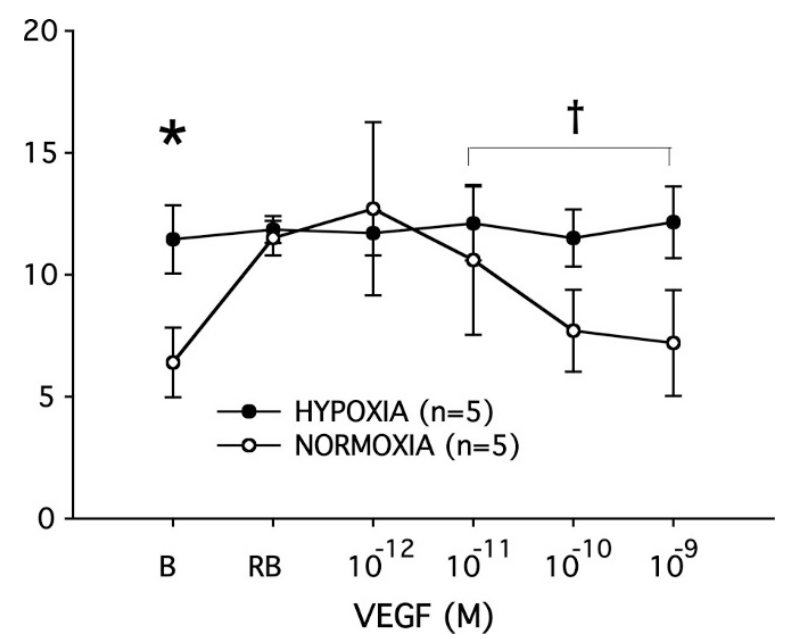

Figure 8. Vasodilator response to VEGF in isolated perfused lungs of newborn piglets that were exposed to normoxia or hypoxia for $14 \mathrm{~d}$. Responses are the lowest perfusion pressure reached for each concentration tested. Values are mean $\pm \mathrm{SD} ; n=5$. B, baseline perfusion pressure; RB, baseline perfusion pressure raised by the addition of the endoperoxide analog U-46619. *Baseline perfusion pressure is higher in hypoxic animals compared with normoxic animals $(p<0.05)$; †significantly reduced vasodilator response in hypoxia compared with normoxia $(p<0.05)$.

a complex formed with two soluble VEGFR1 and a VEGF dimer, as described by others $(13,30)$. Similar complexes of $220 \mathrm{kD}$ have been reported in human umbilical vein endothelial cells (12). Furthermore, Hornig et al. (31) reported that only $5-10 \%$ of the soluble receptor is detected as uncomplexed receptor protein. In pulmonary artery cytosolic fraction, three bands were identified for VEGFR1. As these bands all were specific, they most likely correspond to the immature, intermediate, and mature forms of the receptor (7).

Overall, most functional endothelial VEGF cell signaling described to date is mediated via VEGFR2 or strongly suspected to involve VEGFR2 (3). In hypoxia, the expression of the mature form of VEGFR2 in neonatal piglet pulmonary vasculature is reduced after prolonged exposure, contrasting with the report of Mata-Greenwood et al. (21). As with VEGFR1, the decrease in VEGFR2 was detected even after normalization for endothelial cell mass and protein loading with PECAM expression in the same lung sample. Worsening of pulmonary hypertension after VEGFR2 blockade in chronically hypoxic adult rats (19) or resulting pulmonary hypertension in rats that were treated as newborns with VEGFR blocker (22) supports our hypothesis that VEGFR2 may limit the action of VEGF.

As with VEGFR1, three specific bands were noted for VEGFR2, and they most likely correspond to the immature, intermediate, and mature forms of the receptor (7). The reduction in VEGFR2 expression, namely the 230-kD band, could be due to down-regulation induced by increased VEGF expression. In fact, VEGFR2 expression was shown to be regulated by VEGF (32-34). However, that the immature form of VEGFR2 was increased by hypoxia whereas the mature form was decreased suggests that a defect in receptor maturation may occur in hypoxia. As mentioned above, VEGFR2 is initially synthesized as a $150-\mathrm{kD}$ protein, rapidly glycosylated to a $200-\mathrm{kD}$ intermediate form, and then further glycosylated, at a slower rate, to a $230-\mathrm{kD}$ mature form expressed at cell surface (7). Thus, as hypoxia can affect the expression of glucose transporters (35), it could potentially affect the glycosylation of VEGFR2.

In this study, we have shown that eNOS expression is not affected by hypoxia in the neonatal piglet. This differs from our previous report on eNOS activity (23). This suggests that enzymatic activity can be altered even if expression is unchanged.

We have shown that VEGF can induce significant vasodilation in the neonatal piglet pulmonary vasculature. Recently, we demonstrated that this vasodilator response in the neonatal piglet pulmonary vasculature is mainly due to the release of NO (36). This is in line with the report of Grover et al. (37) in which VEGF caused fetal pulmonary vasodilation by releasing NO through activation of phosphatidylinositol-3-kinase. The vasodilator response to VEGF was abolished in animals that were exposed to hypoxia. The lack of vasodilator response to VEGF is not due to reduced eNOS expression. However, in a previous report (25), eNOS activity was reduced as well as the response to NO, released by SIN-1, and to 8-bromo-cGMP. This suggests that the NO signaling cascade is also affected in the context of hypoxia. Thus, the lack of vasodilator response to VEGF may be due to multiple changes occurring at the receptor level down to the signaling cascade. However, vascular remodeling induced by hypoxia could limit the response to all vasodilators. The expression of iNOS was decreased by exposure to hypoxia. This is in line with our previous report on iNOS activity (23). In endothelial cells from porcine aorta, it was shown that VEGF can induce iNOS expression via VEGFR2 (38). Whether there is link between iNOS and VEGFR2 remains to be shown in the neonatal piglet pulmonary vasculature.

In our experiments, PECAM expression was decreased in hypoxia. This can be due to underrepresentation of endothelial cell proteins in the context of an increased smooth muscle cell mass. This is why normalization of protein expression against PECAM provides a way to ensure that results really reflect changes in expression and not in concentration. We cannot exclude that in our model of hypoxia-induced pulmonary hypertension, PECAM expression may also be affected by hypoxia in the context of cell proliferation (39). In hypoxiainduced pulmonary hypertension, smooth muscle proliferation occurs (26). However, $\alpha$-actin expression was not affected by hypoxia. Others have reported that $\alpha$-actin expression decreases in proliferating neonatal lung vascular cells after hypoxia (40) and that the actin phenotype changes from $\alpha$ - to $\beta$-actin during proliferation $(41,42)$. This may explain the lack of change in $\alpha$-actin expression in our model.

In conclusion, in neonatal hypoxia-induced pulmonary hypertension, VEGF is increased, whereas vasodilation to VEGF is abolished. This reduced vasodilator response may be due to decreased VEGFR2 expression. We speculate that sequestration by VEGFR1, to some extent, may limit the vascular protecting effect of VEGF, thus contributing to the pathophysiologic changes seen in neonatal hypoxia-induced pulmonary hypertension. 


\section{REFERENCES}

1. Breier G 2000 Functions of the VEGF/VEGF receptor system in the vascular system. Semin Thromb Hemost 26:553-559

2. Ferrara N 2001 Role of vascular endothelial growth factor in regulation of physiological angiogenesis. Am J Physiol 280:C1358-C1366

3. Zachary I, Gliki G 2001 Signaling transduction mechanisms mediating biologica actions of the endothelial growth factor family. Cardiovasc Res 49:568-581

4. Tuder RM, Flook BE, Voekel NF 1995 Increased gene expression for VEGF and the VEGF receptors KDR/flk in lungs exposed to acute or to chronic hypoxia. Modulation of gene expression by nitric oxide. J Clin Invest 95:1798-1807

5. Carmeliet P, Ferreira V, Breier G, Pollefeyt S, Kieckens L, Gertsenstein M, Fahrig M, Vandenhoeck A, Harpal K, Eberhardt C, Declercq C, Pawling J, Moons L, Collen D Risau W, Nagy A 1996 Abnormal blood vessel development and lethality in embryos lacking a single VEGF allele. Nature 380:435-439

6. Ferrara N, Carver-Moore K, Chen H, Dowd M, Lu L, O'Shea KS, Powell-Braxton L, Hillan KJ, Moore MW 1996 Heterozygous embryonic lethality induced by targeted inactivation of the VEGF gene. Nature 380:439-442

7. Takahashi T, Shibuya M 1997 The 230-kDa mature form of KDR/flk-1 (VEGF receptor-2) activates the PLC-gamma pathway and partially induces mitotic signals in NIH3T3 fibroblasts. Oncogene 14:2079-2089

8. de Vries C, Escobedo JA, Ueno H, Houck K, Ferrara N, Williams LT 1992 The fms-like tyrosine kinase, a receptor for vascular endothelial growth factor. Science 255:989-991

9. Partovian C, Adnot S, Raffestin B, Louzier V, Levame M, Mavier IM, Lemarchand P, Eddahibi S 2000 Adenovirus-mediated lung vascular endothelial growth facto overexpression protects against hypoxic pulmonary hypertension in rats. Am J Respir Cell Mol Biol 23:762-771

10. Shen BQ, Lee DY, Zioncheck TF 1999 Vascular endothelial growth factor governs endothelial nitric-oxide synthase expression via a KDR/Flk-1 receptor and a protein kinase C signaling pathway. J Biol Chem 274:33057-33063

11. Banks RE, Forbes MA, Searles J, Pappin D, Canas B, Rahman D, Kaufmann S, Walters CE, Jackson A, Eves P, Linton G, Keen J, Walker JJ, Selby PJ 1998 Evidence for the existence of a novel pregnancy-associated soluble variant of the vascular endothelial growth factor receptor, Flt-1. Mol Hum Reprod 4:377-386

12. Kendall RL, Thomas KA 1993 Inhibition of vascular endothelial cell growth factor activity by an endogenously encoded soluble factor. Proc Natl Acad Sci USA 90:10705-10709

13. Kendall RL, Wang G, Thomas KA 1996 Identification of a natural soluble form of vascular endothelial growth factor receptor, FLT-1, and its heterodimerization with KDR. Biochem Biophys Res Commun 226:324-328

14. Moss AJ, Emmanouilides G, Duffie ER Jr 1963 Closure of the ductus arteriosus in the newborn infant. Pediatrics 32:25-30

15. Kinsella JP, Abman SH 1995 Recent developments in the pathophysiology and treatment of persistent pulmonary hypertension of the newborn. J Pediatr 126:853864

16. Levin DL, Heymann MA, Kitterman JA, Gregory GA, Phibbs RH, Rudolph AM 1976 Persistent pulmonary hypertension of the newborn. J Pediatr 89:626-630

17. Lassus P, Turanlahti M, Heikkilä P, Andersson LC, Nupponen I, Sarnesto A, Andersson S 2001 Pulmonary vascular endothelial growth factor and Flt-1 in fetuses, in acute and chronic lung disease, and in persistent pulmonary hypertension of the newborn. Am J Respir Crit Care Med 164:1981-1987

18. Deleted in proof

19. Taraseviciene-Stewart L, Kasahara Y, Alger L, Hirth P, Mc Mahon G, Waltenberger J, Voekel NF, Tuder RM 2001 Inhibition of the VEGF receptor 2 combined with chronic hypoxia causes cell death-dependent pulmonary endothelial cell proliferation and severe pulmonary hypertension. FASEB J 15:427-438

20. Grover TR, Parker TA, Zenge JP, Markham NE, Kinsella JP, Abman SH 2003 Intrauterine hypertension decreases lung VEGF expression and VEGF inhibition causes pulmonary hypertension in the ovine fetus. Am J Physiol 284:L508-L517

21. Mata-Greenwood E, Meyrick B, Soifer SJ, Fineman JR, Black SM 2003 Expression of VEGF and its receptors Flt-1 and Flk-1/KDR are altered in lambs with increased pulmonary blood flow and pulmonary hypertension. Am J Physiol 285:L222-L231
22. Le Cras TD, Markham NE, Tuder RB, Voelkel NF, Abman SH 2002 Treatment of newborn rats with a VEGF receptor inhibitor causes pulmonary hypertension and abnormal lung structure. Am J Physiol 283:L555-L562

23. Berkenbosch JW, Baribeau J, Perreault T 2000 Decreased synthesis and vasodilation to nitric oxide in piglets with hypoxia-induced pulmonary hypertension. Am J Physiol 278:L276-L283

24. Gosselin R, Gutkowska J, Baribeau J, Perreault T 1997 Endothelin receptor changes in hypoxia-induced pulmonary hypertension in the newborn piglet. Am J Physiol 273:L72-L79

25. Perreault T, Baribeau J, Gosselin R, Gutkowka J 1997 Reduced vasodilator response to ANF in hypoxia-induced pulmonary hypertension in the newborn piglet. Am J Physiol 273:L289-L295

26. Perreault T, Berkenbosch JW, Barrington KJ, Decker ER, Wu C, Brock TA, Baribeau J 2001 TBC3711, an ETA receptor antagonist, reduces neonatal hypoxia-induced pulmonary hypertension in piglets. Pediatr Res 50:374-383

27. Christou H, Yoshida A, Arthur V, Morita T, Kourembanas S 1998 Increased vascula endothelial growth factor production in the lungs of rats with hypoxia-induced pulmonary hypertension. Am J Respir Cell Mol Biol 18:768-776

28. Tuder RM, Flook BE, Voelkel NF 1995 Increased gene expression for VEGF and the VEGF receptors KDR/Flk and Flt in lungs exposed to acute or to chronic hypoxia Modulation of gene expression by nitric oxide. J Clin Invest 95:1798-1807

29. Shehata SM, Mooi WJ, Okazaki T, El-Banna I, Sharma HS, Tibboel D 1999 Enhanced expression of vascular endothelial growth factor in lungs of newborn infants with congenital diaphragmatic hernia and pulmonary hypertension. Thorax $54: 427-431$

30. Wiesmann C, Fuh G, Christinger HW, Eigenbrot C, Wells JA, de Vos AM 1997 Crystal structure at $1.7 \AA$ resolution of VEGF in complex with domain 2 of the Flt-1 receptor. Cell 91:695-704

31. Hornig C, Barleon B, Ahmad S, Vuorela P, Ahmed A, Weich HA 2000 Release and complex formation of soluble VEGFR-1 from endothelial cells and biological fluids. Lab Invest 80:443-454

32. Duval M, Bédard-Goulet S, Delisle C, Gratton JP 2003 Vascular endothelial growth factor-dependent down-regulation of Flk-1/KDR involves Cbl-mediated ubiquitination. Consequences on nitric oxide production from endothelial cells. J Biol Chem 278:20091-20097

33. Kremer C, Breier G, Risau W, Plate KH 1997 Up-regulation of flk-1/vascular endothelial growth factor receptor 2 by its ligand in a cerebral slice culture system. Cancer Res 57:3852-3859

34. Shen BQ, Lee DY, Gerber HP, Keyt BA, Ferrara N, Zioncheck TF 1998 Homologous up-regulation of KDR/Flk-1 receptor expression by vascular endothelial growth factor in vitro. J Biol Chem 273:29979-29985

35. Yan SF, Lu J, Zou YS, Kisiel W, Mackman N, Leitges M, Steinberg S, Pinsky D, Stern D 2000 Protein kinase C- $\beta$ and oxygen deprivation. A novel Egr-1 dependent pathway for fibrin deposition in hypoxic vasculature. J Biol Chem 275:11921-11928

36. Janvier AF, Nadeau S, Baribeau J, Perreault T2003 Vasodilation to vascular endothelial growth factor (VEGF) may involve a non-nitric oxide (NO), non-prostacyclin PGI2) mechanism in the neonatal piglet pulmonary vasculature. Pediatr Res 53:432A

37. Grover TR, Zenge JP, Parker TA, Abman SH 2002 Vascular endothelial growth factor causes pulmonary vasodilation through activation of the phosphatidylinositol3-kinase-nitric oxide pathway in the late-gestation ovine fetus. Pediatr Res 52:907912

38. Kroll J, Waltenberger J 1998 VEGF-A induces expression of eNOS and iNOS in endothelial cells via VEGF receptor-2 (KDR). Biochem Biophys Res Commun 252:743-746

39. Enciso JM, Gratzinger D, Camenisch TD, Canosa S, Pinter E, Madri JA 2003 Elevated glucose inhibits VEGF-A-mediated endocardial cushion formation: modulation by PECAM-1 and MMP-2. J Cell Biol 160:605-615

40. Skalli O, Vandekerckhove J, Gabbiani G 1987 Actin-isoform pattern as a marker of normal or pathological smooth-muscle and fibroblastic tissues. Differentiation 33:232-238

41. Kocher O, Gabbiani G 1986 Expression of actin mRNAs in rat aortic smooth muscle cells during development, experimental intimal thickening and culture. Differentiation $32: 245-25$

42. Clowes AW, Clowes MM, Kocher O, Ropraz P, Chaponnier C, Gabbiani G 1988 Arterial smooth muscle cells in vivo: relationship between actin isoform expression and mitogenesis and their modulation by heparin. J Cell Biol 107:1939-1945 